\title{
Sublingual versus vaginal misoprostol for medical termination of pregnancy: a comparative study
}

\section{Ayswarya Shanmugam*, Seethesh Ghose, Pallavee Parida, Jasmina Begum}

\begin{abstract}
Department of Obstetrics and Gynaecology, Mahatma Gandhi Medical College and Research Institute, Puducherry,
\end{abstract} India

Received: 19 January 2016

Revised: 12 September 2016

Accepted: 13 September 2016

\author{
*Correspondence: \\ Dr. Ayswarya Shanmugam, \\ E-mail: ayswarya.mbbs@gmail.com
}

Copyright: (c) the author(s), publisher and licensee Medip Academy. This is an open-access article distributed under the terms of the Creative Commons Attribution Non-Commercial License, which permits unrestricted non-commercial use, distribution, and reproduction in any medium, provided the original work is properly cited.

\begin{abstract}
Background: Medical abortion with a combination of mifepristone and a prostaglandin analogue, as an alternative to surgical abortion in early pregnancy.

Methods: This randomized comparative study was conducted for 60 women with pregnancy up to 20 weeks period of gestation after getting approval from the institutional ethics committee and informed consent from the patient. Patients were divided into 2 groups based on computer generated random number. Patients in one group had received 200mg mifepristone orally and after 24 hours $400 \mathrm{mcg}$ of misoprostol sublingually after admission in to labour ward. Dose was repeated every 6 hours up to maximum of 5 doses. Patients in other group had received 200mg mifepristone orally and after 24 hours $400 \mathrm{mcg}$ of misoprostol vaginally after admission in to labour ward. Dose was repeated every 6 hours up to maximum of 5 doses.

Results: The maternal age distribution, parity and gestational age in the two groups were found to be comparable. Requirement of mean dose of misoprostol in sublingual and vaginal were $1300 \mathrm{mcg}, 1253 \mathrm{mcg}$ respectively. The mean induction and abortion interval was $15.31 \pm 7.9$ and $15.41 \pm 7.8$ hours in sublingual and vaginal respectively. The complete abortion rate was $80 \%$ and $83.3 \%$ in sublingual and vaginal groups. The rates of side effects were similar in both groups respectively.

Conclusions: There is no significant difference in efficacy and side effects between sublingual and vaginal route of misoprostol for termination of pregnancy.
\end{abstract}

Keywords: Mifepristone, Misoprostol, MTP, Sublingual, Vaginal, Dose

\section{INTRODUCTION}

WHO define abortion as pregnancy termination prior to 20 weeks of gestation or with a fetus born weighing less than 500 gms. ${ }^{1}$ Safe and legal abortion has played an important role for improving women health and quality of life. $^{2}$ A 2014 systematic analysis of worldwide data estimates that approximately $8 \%$ of all maternal deaths are attributable to unsafe abortion and related complications. $^{3}$

Spontaneous abortion occurs in nearly $20 \%$ of confirmed pregnancy. Out of these $80 \%$ occurs in first trimester.
Second trimester abortions constitute $10-15 \%$ of induced abortions. Second trimester abortion contributes to $2 / 3^{\text {rd }}$ of major abortion related complications.4 Vacuum aspiration is the conventional method of evacuation of uterus and is associated with $4-10 \%$ of complications like bleeding, infection, uterine perforation and decreased fertility. ${ }^{5}$

Since 1971, abortion has been legalised in our country. ${ }^{6}$ Historically, it has been noticed that there is significant shortage of facilities approved for abortion provision in India, and distribution of these facilities have been uneven across the states. Despite the increase in the 
number of approved facilities over the years from 1,877 in 1976 to 9,859 in 2002 to 12,510 in 2010 access to safe abortion remains inadequate, especially in rural areas., ${ }^{7,8}$ Provisional government figures estimate that 621,748 abortions were performed in 2011-2012, and the number increased slightly to 636,306 in 2012-2013, indicating an annual rate of about two abortions per 1,000 women aged $15-49$ in $2013 .^{9,10}$

In India, elective termination of pregnancy is a commonly performed gynaecological procedure. ${ }^{11}$ Medical methods like prostaglandin E1 analoguemisoprostol is commonly used along with Mifepristone up to second trimester abortions. Mifepristone acts by inhibiting the effect of progesterone by binding to the progesterone receptor. Thus, in early pregnancy, mifepristone administration results in regular uterine contractility and increased sensitivity of prostaglandins. ${ }^{12}$ Misoprostol acts as a cervical ripening and uterotonics agent. It is widely used for termination of pregnancy and combined with mifepristone for medical abortion. It is inexpensive and stable at room temperature.

Surgical procedure is associated with faster results, but it can lead to more complications like cervical incompetence, uterine synechiae and uterine perforations. So, nowadays medical method is the treatment of choice for medical termination of pregnancy.

Different doses and routes of administration of misoprostol in both first and second trimester have been investigated and results are compared, but optimal dose and route have not been properly identified. ${ }^{13-15}$ Due to its rapid absorption, sublingual route reaches its peak concentration in a short time and has the highest bioavailability. Vaginal route causes prolonged regular uterine contractions and has fewer side effects after administration. ${ }^{16}$ So, the present study is done to compare the efficacy of sublingual and vaginal misoprostol for medical abortion up to 20 weeks of gestation.

\section{METHODS}

This randomized comparative study was conducted in Mahatma Gandhi Medical College and Research Institute, Pondicherry, India, a tertiary care centre, between January 2014 and July 2015 to compare the efficacy of sublingual and vaginal misoprostol for medical termination of pregnancy after obtaining the ethical committee clearance.

One group with gestational age of $<20$ weeks had received Mifepristone $200 \mathrm{mg}$ orally and after 24 hours patient had received $400 \mu \mathrm{g}$ of Misoprostol sublingually after admission into labour ward. Misoprostol dose was repeated $6^{\text {th }}$ hours up to a maximum of five doses.

Other group with gestational age of $<20$ weeks had received Mifepristone $200 \mathrm{mg}$ orally and after 24 hours patient had received $400 \mu \mathrm{g}$ of Misoprostol vaginally after admission into labour ward. Misoprostol dose was repeated $6^{\text {th }}$ hourly up to a maximum of five doses.

Patients were observed in labour room from the time of first misoprostol administration. Time was noted when patient complained of expulsion of products of conception and completeness of abortion was checked with trans-vaginal ultrasound examination immediately and after 72 hours by endometrial thickness measurement i.e. less than $17 \mathrm{~mm}$ of endometrial thickness was considered as complete abortion.

If patient failed to expel within 72 hours with endometrial thickness of $>17 \mathrm{~mm}$, it was considered as failed management. They underwent further management according to department protocol. Patient's vitals were monitored $6^{\text {th }}$ hours and side effects were noted.

All data was entered into a data collection proforma sheet (appendix 1) and were entered into Excel (MS Excel 2011). The Sheet was divided into different parameters for comparing sublingual and vaginal group and data was entered. Data analysis was performed by using SPSS, All outcomes were assessed using Chi-squared test and independent t-test.

\section{Study parameters}

\section{Primary outcome}

- Induction - abortion interval

- Complete abortion at 72 hours

- Total dose of misoprostol required for complete abortion.

\section{Secondary outcome}

- Need for surgical evacuations

- Side effects - unpleasant taste, diarrhoea, fever, vomiting, shivering.

\section{RESULTS}

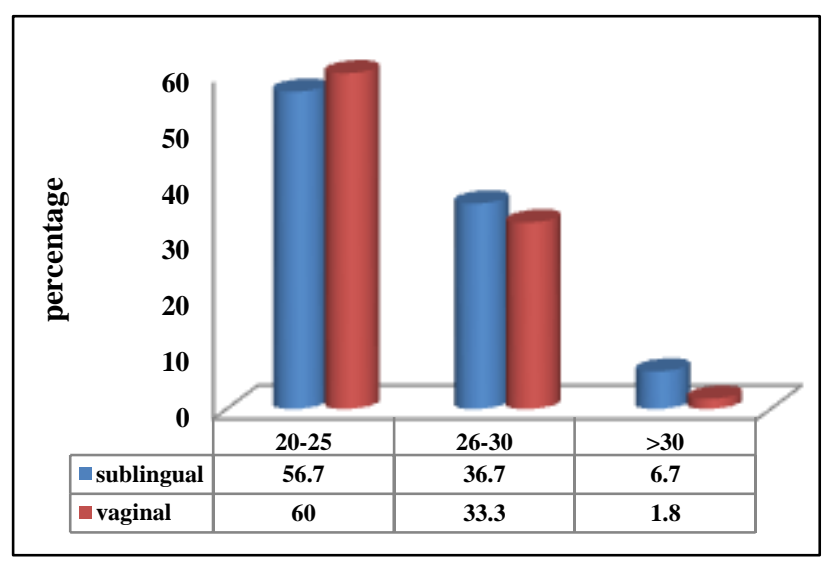

Figure 1: Maternal age distribution. 
Age

Both the groups were age matched (Figure 1).

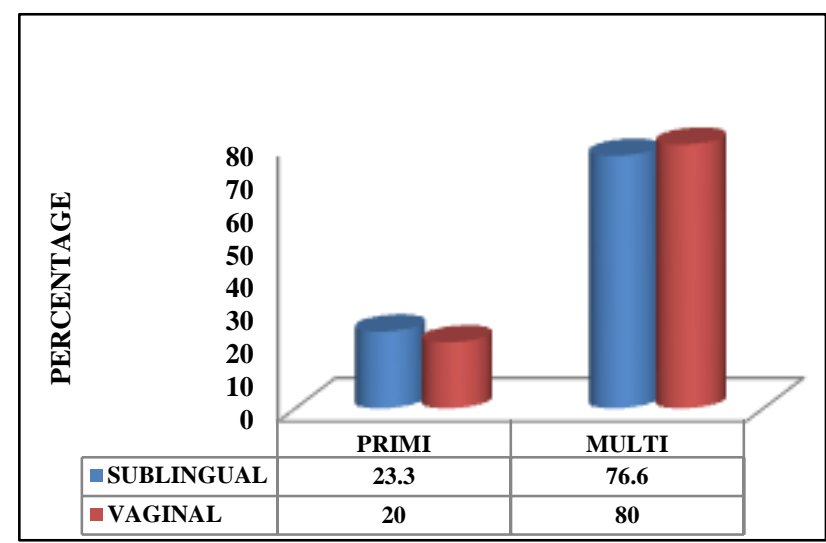

Figure 2: Parity distribution.

\section{Parity}

Maximum no of patients were multipara in both groups (Figure 2).

\section{Gestational age}

Both the groups were comparable (Figure 3).

\section{Number of doses of misoprostol required in sublingual and vaginal groups}

The mean doses of misoprostol required were $1300 \mathrm{mcg}$ and $1253 \mathrm{mcg}$ in both sublingual and vaginal groups. Dose of misoprostol required for expulsion were statistically not significant between sublingual and vaginal groups $(\mathrm{P}=0.985)$ (Table 1$)$.

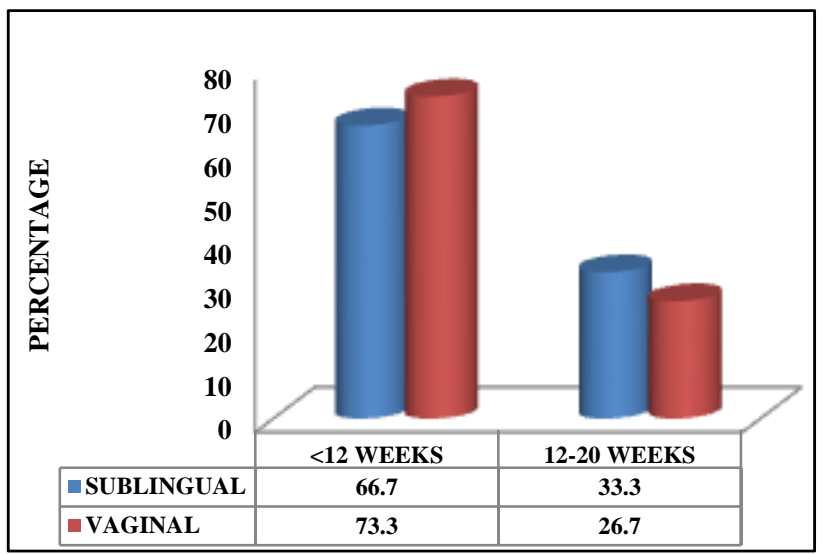

Figure 3: Gestational age.

Table 1: Requirement of number of doses of misoprostol in sublingual and vaginal groups.

\begin{tabular}{|lllllllll|}
\hline No of doses & No & Primi & Multi & \% & No & Primi & Multi & \% \\
\hline 1 & 3 & 1 & 2 & 10 & 3 & 1 & 2 & 10 \\
\hline 2 & 10 & 3 & 7 & 33.3 & 12 & 3 & 9 & 40 \\
\hline 3 & 4 & 1 & 3 & 13.3 & 3 & 0 & 3 & 10 \\
\hline 4 & 2 & 0 & 2 & 6.7 & 2 & 0 & 2 & 6.7 \\
\hline 5 & 11 & 2 & 9 & 36.7 & 10 & 2 & 8 & 33.3 \\
\hline Mean dose & & $1300 \mathrm{mcg}$ & & & $1253 \mathrm{mcg}$ & & & \\
\hline
\end{tabular}

$\mathrm{P}$ value-0.985.

\section{Induction to abortion interval in sublingual and vaginal groups}

The mean induction abortion interval was $15.31 \pm 7.9$ hours and $15.41 \pm 7.8$ hours in both sublingual and vaginal groups respectively. Induction abortion interval is statistically not significant in both groups $(p=0.987)$ (Table 2).

\section{Side effects in sublingual and vaginal groups}

Among the 60 patients studied, three patients had side effects in sublingual group out of which one had vomiting (33\%), one had fever $(33 \%)$ and one had shivering (33\%). Three patients in vaginal group had side effects out of which two had fever $(66.7 \%)$ and one had shivering $(33.3 \%)$. Incidences of side effects were common in both groups $(\mathrm{P}=0.513)$ (Table 3$)$.

\section{Completeness of abortion in sublingual and vaginal groups}

In sublingual and vaginal groups, $81.7 \%$ patients had complete abortion and $18.3 \%$ had incomplete abortion. In sublingual group, $80 \%$ had complete abortion and $20 \%$ had incomplete abortion. In vaginal group, $83.3 \%$ had complete abortion and $16.7 \%$ had incomplete abortion. Completeness of abortion is statistically not significant in both sublingual and vaginal groups $(\mathrm{P}=0.739)$ (Figure 4). 


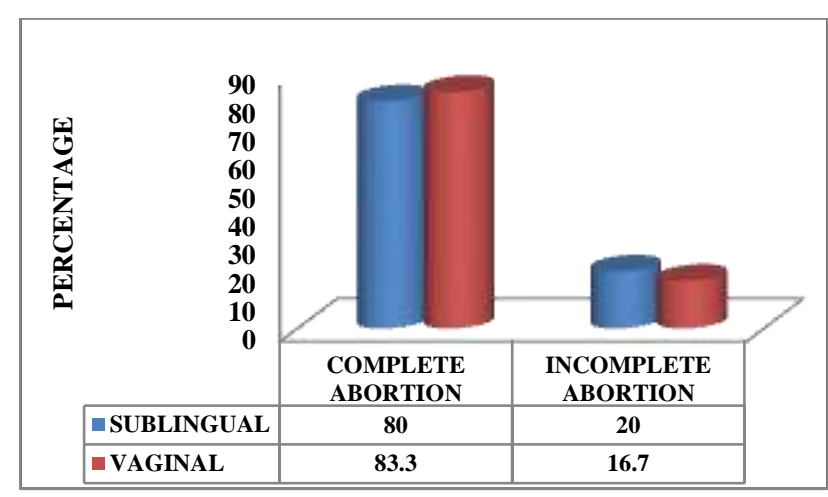

Figure 4: Completeness of abortion.

\section{Additional methods for termination}

Altogether in both groups, $33.3 \%$ were treated with medical management and $66.7 \%$ were treated with surgical management. In sublingual group, $42.9 \%$ were treated with medical management and $57.1 \%$ were treated with surgical management. In vaginal group, $20 \%$ were treated with medical management and $80 \%$ were treated with surgical management. Mode of treatment were statistically not significant in both groups $(P=0.408)$ (Table 4).

Table 2: induction to abortion interval in both sublingual and vaginal groups.

\begin{tabular}{|lllll|}
$\begin{array}{l}\text { Induction to } \\
\text { abortion } \\
\text { interval }\end{array}$ & \multicolumn{2}{l}{ Sublingual } & \multicolumn{2}{l|}{ Vaginal } \\
\hline & No & $\%$ & No & \% \\
\hline 6 Hours & 3 & 2.5 & 4 & 15.4 \\
\hline 6-12 Hours & 10 & 41.7 & 11 & 42.3 \\
\hline 12-18 Hours & 4 & 16.7 & 3 & 11.5 \\
\hline 18-24 Hours & 2 & 8.3 & 2 & 7.7 \\
\hline 24-30 Hours & 5 & 20.8 & 6 & 23.1 \\
\hline Mean \pm SD & $15.31 \pm 7.9$ Hours & $15.41 \pm 7.8$ Hours \\
\hline P value-0.987 & \multicolumn{5}{|l}{} \\
\hline
\end{tabular}

Table 3: comparison of side effects in sublingual and vaginal groups.

\begin{tabular}{|c|c|c|c|c|c|}
\hline Side effects & \multicolumn{2}{|c|}{ Sublingual } & \multicolumn{2}{|c|}{ Vaginal } & P value \\
\hline & No & $\%$ & No & $\%$ & \\
\hline Fever & 1 & 33.3 & 1 & 33.3 & \\
\hline Vomiting & 1 & 33.3 & 0 & 0 & 0.513 \\
\hline Shivering & 1 & 33.3 & 2 & 66.7 & \\
\hline
\end{tabular}

Table 4: Additional requirement for termination in sublingual and vaginal groups.

\begin{tabular}{|llllll|}
\hline & Additional method Sublingual & \multicolumn{2}{c}{ Vaginal } & P value \\
\cline { 1 - 5 } & No & \% & No & \% & \\
\cline { 1 - 5 } Medical methods & 3 & 42.9 & 1 & 20 & \multirow{2}{*}{0.408} \\
\cline { 1 - 5 } Surgical methods & 4 & 57.1 & 4 & 80 & \\
\hline
\end{tabular}

\section{DISCUSSION}

Up to 42 million abortions are done every year. ${ }^{17}$ Induced abortion has been facilitated by various methods including the use of sharpened tools, herbal abortifacients, physical trauma and other traditional methods in the early days. In the year 1970 an alternative method for first trimester pregnancy termination emerged with the availability of prostaglandin and antiprogesterone in the year 1980s. Mifepristone and misoprostol for termination of early pregnancy is approved by world health organization. Urquhatt et al suggested mifepristone and a prostaglandin would be an effective method for pregnancy termination for early medical abortion. ${ }^{18}$

Age, maternal age and paritity are comparable with the other studies.

Kulier $\mathrm{R}$ et al reduced the dose of mifepristone from 600 $\mathrm{mg}$ to $200 \mathrm{mg}$ and combined with $400 \mathrm{mcg}$ of misoprostol. They concluded that a combined regimen with a prostaglandin is effective than use of prostaglandin alone. In a study done by Prasad $\mathrm{R}$ et al reported a single dose of $200 \mathrm{mg}$ of mifepristone is as effective and useful for the management of missed abortion. ${ }^{19}$ Our study confirms that single dose of $200 \mathrm{mg}$ mifepristone is useful prior to misoprostol for medical termination of pregnancy.

Gronlund et al, used $400 \mathrm{mcg}$ single dose misoprostol vaginally and found efficacy to be $71 \% .{ }^{20}$ Ramsey et al, used $400 \mathrm{mcg} 4^{\text {th }}$ hourly up to 5 doses vaginally and reported increase in efficacy up to $95 \% .^{21}$ Kushwah DS et al studied mifepristone $200 \mathrm{mg}$ followed by misoprostol $600 \mathrm{mcg}$ sublingually and dose requirement were as follows, one (86\%), two (4\%), three $(0 \%)$ and four $(10 \%)$. In the oral group, dose requirement were one $(62 \%)$, two $(10 \%)$ three $(10 \%)$ and four (18\%) respectively. ${ }^{22}$ In a study done by Hooja $\mathrm{N}$ et al, the mean dose required in sublingual was $1564 \mathrm{mcg}$ and in vaginal group was $2044 \mathrm{mcg}$ and this was statistically significant $(<0.001)$. Whereas In our study the mean dose required in sublingual was 1300 and in vaginal was 1253 mcg respectively. The dose requirement in our study is less in comparison to study done by Hooja $\mathrm{N}$ et al.

In a study done by Pandey et al, mean induction abortion interval was $15.4 \pm 8.08$ hours in sublingual group and it was $14.4 \pm 5.3$ hours in vaginal group. Hooja $\mathrm{N}$ et al, found induction abortion interval to be 18.24 hours and 18.12 hours in sublingual and vaginal groups respectively. In our study, the mean induction abortion interval was 15.31 \pm 7.9 hours in sublingual and 15.41 \pm 7.8 hours in the vaginal group.

In a study done by Hooja $\mathrm{N}$ et al, there was no difference in the side effects in the both vaginal and sublingual groups (50\% and $75 \%$ ). Pandey et al study also suggested that the side effects were comparable in both the groups. 
Only significant difference being fever which was higher in vaginal group. In our study, the incidence of side effects fever, vomiting and shivering were $(33.3 \%)$ in sublingual group and in vaginal group - fever $(33.3 \%)$ and shivering $(66.7 \%)$. Our study has fewer side effects when compared to other studies.

In a study done by Pandey et al, where $75 \%$ and $70 \%$ of patients had complete abortion with sublingual and vaginal misoprostol respectively. This study corresponds with the other study done by Tang et al, that success rate was $91 \%$ in case of sublingual group and $95 \%$ in the vaginal group. In our study, $80 \%$ patients had complete abortion in the sublingual group as compared to vaginal group in which $83.3 \%$ of the patient had complete abortion. Low rate of completeness may be due to stringent ultrasonographic criteria i.e endometrial thickness less than $17 \mathrm{~mm}$.

In a study done by Tang OS et al, 17 patients in sublingual group and 16 patients in vaginal group required surgical evacuation for incomplete abortion and this was not statistically significant. In our study 3 patients in sublingual group and 1 patient in vaginal group required additional medical method. Likewise 4 patient in both sublingual and vaginal group required surgical evacuation and statistically not significant.

Limitations of this study were, sample size was less due to limited study period. Although a larger cohort is required to get more dependable result.

\section{CONCLUSION}

Both mifepristone and misoprostol both sublingual and vaginal administration of misoprostol are almost equally effective for terminating first and second trimester pregnancies as far as mean induction abortion interval, need for surgical evacuation, failure rates are considered.

\section{Funding: No funding sources}

Conflict of interest: None declared

Ethical approval: The study was approved by the Institutional Ethics Committee

\section{REFERENCES}

1. Cunningham FG, Halvorson, Lisa M. First trimester abortion. In: Hoffman BL, Schorge JO, Bradshaw KD (editors). Williams Gynaecology $2^{\text {nd }}$ ed, New York, NY: Mc Graw - Hill Companies; 2012:170-97.

2. Dhillon BS, Chandhiok N, Kambo I, Saxena NC. Induced abortion and concurrent adoption of contraception in rural areas of India. Ind J Med Sci. 2004;58(11):478-84.

3. Say L, Chou D, Gemmill A, Moller AB. Global causes of maternal death: a WHO systematic analysis. Lancet Glob Health. 2014;2(6):e323-33.

4. Drey EA, Foster DG, Jackson RA, Lee SJ, Cardenas LH, Darney PD, et al. Risk factors associated with presenting for abortions in second trimester. Obstet Gynaecol. 2006;107(1):128-35.

5. Ngai SW, Chand YM, Tang O, Ho PC. Vaginal misoprostol as medical treatment for first trimester spontaneous miscarriage. Hum Reprod. 2001;16(7):1493-6.

6. Government of India, The Medical Termination of Pregnancy Act, No 34, 1971. Available at https://www.guttmacher.org/pubs/Abortion-IndiaLit-Review.

7. Jejeebhoy SJ, Kalyanwala S, Mundle S, Tank J, Zavier AJ, Kumar R, et al. Feasibility of expanding the medication abortion provider base in India to include Ayurvedic physicians and nurses. Int Perspect Sex Reprod Health. 2012;38(3):133-42.

8. Ministry of Health and Family Welfare, Family Welfare Statistics of India, New Delhi: Ministry of Health and Family Welfare; 2011.

9. Ministry of Health and Family Welfare, Health and Family Welfare Statistics of India 2013, New Delhi: Ministry of Health and Family Welfare, Statistics Division, 2013. Available at https://nrhmmis.nic.in/PubFWStatistics\%202013/Complete\%20B ook.

10. Special tabulations of data from department of economic and social affairs, population division, UN, World Population Prospects: The 2012 Revision, DVD, NewYork: UN, 2013. Available at http://esa.un.org/unpd/wpp/Publications/Files/WPP2 012_HIGHLIGHTS.

11. Goyel BK, Singh G. Midtrimester MTP using endocervical PGE2 gel and serial intramuscular carboprost. Med J Armed Forces India. 2000;56:379.

12. Cadepond F, Ulmann A, Baulieu EE. RU 486 (mifepristone) mechanism of action and clinical uses. Ann Rev of Med. 1997;48:129-56.

13. Zieman M, Fong S, Benowitz NL, Banskter D, Darney PD. Absorption kinetics of misoprostol with oral or vaginal administration. Obstet Gynecol. 1997;90(1):88-92.

14. Tang OS, Schweer H, Seyberth HW, Lee SWH, Ho PC. Pharmacokinetics of different routes of administration of misoprostol. Human Reprod. 2002;17:332-6.

15. Meckstroth KR, Whitaker AK, Bertisch S, Goldberg AB, Darney PD. Misoprostol administered by epithelial routes: drug absorption and uterine response. Obstet Gynecol. 2006;108:582-90.

16. Tanha FD, Golgachi T, Niroom N, Ghaharzadeh M, Nasr R. Sublingual versus vaginal misoprostol for second trimester termination: a randomized clinical trial. Arch Gynecol Obstet. 2013;287(1):65-9.

17. Sedgh G, Henshaw SK, Singh S, Bankole A, Drescher J. Legal abortion worldwide: incidence and recent trends. Int fam plan perspect. 2007;33(3):10616.

18. Urquhart DR, Templeton AA, Shinewi F, Chapman M, Hawkins K, McGarry J. The efficacy and tolerance of mifepristone and prostaglandin in 
termination of pregnancy of less than 63 days gestation: UK Multicentre Study-final results. Contraception. 1997;55:1-5.

19. Divya PR, Neelima NV. Safety and efficacy of using mifepristone and misoprostol combination in termination of first trimester missed abortion - a prospective study. Int $\mathbf{J}$ medical and applied science. 2014;(3):14-9.

20. Gronlund A, Gronlund L, Clevin L, Andersen B, Palmgren N, Lidegaard $\mathrm{O}$, et al. Management of missed abortion, comparison of medical treatment with either mifepristone+misoprostol or misoprostol alone with surgical evacuation. A multi-centre trial in
Copenhagen, Denmark. Acta Obstet Gynecol Scand. 2002;81:1060-5.

21. Ramsey PS, Savage K, Lincoln T, Owen J. Vaginal misoprostol versus concentrated oxytocin and vaginal PGE2 for second trimester labour induction. Obstet Gynecol. 2004;104:138-45.

22. Kushwah DS, Kushwah B, Salman MT, Verma VK. Acceptability and safety profile of oral and sublingual misoprostol for uterine evacuation following early fetal demise. Indian $\mathrm{J}$ Pharmacol. 2011;43(3):306-10.

Cite this article as: Shanmugam $\mathrm{A}$, Ghose $\mathrm{S}$, Parida P, Begum J. Sublingual versus vaginal misoprostol for medical termination of pregnancy: a comparative study. Int J Reprod Contracept Obstet Gynecol 2016;5:3398-403. 